\title{
Retraction Note to: Human-computer interaction using vision-based hand gesture recognition systems: a survey
}

\author{
Haitham Hasan ${ }^{1}$ Sameem Abdul-Kareem ${ }^{1}$
}

Published online: 15 February 2017

(C) The Natural Computing Applications Forum 2017

\section{Retraction Note to: Neural Comput \& Applic \\ (2014) 25:251-261 \\ DOI 10.1007/s00521-013- 1481-0}

The Editor-in-Chief and the Publisher retract the abovementioned article due to self-plagiarism. The article has significant overlap with two other publications by the same co-author:

- Haitham Badi, Mohammed Fadhel, Sana Sabry, Mohamed Jasem, A Survey on Human-Computer Interaction Technologies and Techniques, International Journal of Data Science and Analytics (2016) 2:1. doi:10.1007/s41060-016-0018-x

- Haitham Badi, A Survey on Recent Vision-Based Gesture Recognition, Intelligent Industrial Systems (2016) 2:2. doi:10.1007/s40903-016-0046-9

The online version of the original article can be found under doi:10.1007/s00521-013-1481-0.

Haitham Hasan

haitham@siswa.um.edu.my

1 Department of Artificial Intelligence, Faculty of Computer Science and Information Technology, University of Malaya, 50603 Kuala Lumpur, Malaysia 